\title{
Arte, interdisciplinaridade e infância: experiências estéticas, artísticas e brincantes no sarau Toda Criança é um Poema
}

\begin{abstract}
Resumo: Este texto reflete sobre experiências artísticas vivenciadas na infância, tendo como princípio fundamental a compreensão da criança como ser capaz de fruir, criar e produzir culturas. Para dar conta dessa discussão foi realizada uma pesquisa bibliográfica contemplando autores significativos. Além disso, foi desenvolvida uma pesquisa de campo tomando como base o III Sarau Infantil Toda Criança é um Poema, ação integrante do Projeto de Extensão Balaio de Sensibilidades, vinculado à Faculdade de Educação da Universidade Federal da Bahia. Nessa edição, participaram crianças de 4 a 8 anos e foi possível observar quatro tipos de espaços: visualidades, musicalidades, brincadeiras e interações e poemas e histórias, organizados sob a referência de linguagens diversificadas, porém de forma interdisciplinar. O estudo revelou que o campo das culturas infantis abrange áreas distintas do conhecimento artístico e formas próprias e variadas de interações e de produção de saberes e experiências. Além disso, foi possível concluir como princípios basilares da experiência estética do Sarau Infantil: a) diversidade de vivências e de linguagens artísticas; b) espaço-tempo organizado e caracterizado por possibilidades de desordenamento, flexibilidade e reversibilidade; c) liberdade de ação da criança em escolher as formas de interação com as artes; d) relação dialógica entre adultos e crianças. Por fim, o Sarau Infantil pode ser considerado uma experiência estética, artística, brincante, plural, livre e com diferentes possibilidades de interações entre crianças, artistas, escolas, acadêmicos e brincantes.
\end{abstract}

Palavras-chave: Infância. Estética. Arte. Cultura infantil. Brincar.

\section{Da arte de introduzir}

Ao longo da história, os estudos teóricos voltados para a infância sempre foram de interesse das ciências da saúde infantil, da psicologia e da puericultura. A infância enquanto objeto de estudo, por excelência, ficou a cargo da psicologia da aprendizagem e de correntes teóricas que a concebiam, numa perspectiva biológica, apenas como uma idade efêmera e destinada à maturação das estruturas internas. A psicologia, desse modo, travava alguns diálogos com outras áreas do conhecimento humano, a exemplo da educação que assumiu contornos demasiadamente desenvolvimentistas para o entendimento da infância. Já as ciências humanas como a história, a antropologia, a filosofia e a sociologia, apesar de serem áreas relevantes para ampliação de estudo sobre a criança, apresentavam pouco interesse nesse campo de pesquisa.
Leila da Franca Soares Universidade Federal da Bahia leilafrancas@gmail.com

Cilene Nascimento Canda Universidade Federal da Bahia cilenecanda@yahoo.com.br

Urânia Auxiliadora Maia Oliveira

Universidade Federal da Bahia uraniamaia@gmail.com 
(1) O Sarau Infantil é uma ação formativa integrante do Projeto de Extensão Balaio de Sensibilidades coordenada pela professora $\mathrm{Dr}^{\mathrm{a}}$

Cilene Canda e pela professora

Dr ${ }^{\mathrm{a}}$ Leila Soares, da Faculdade de

Educação da Universidade Federa

da Bahia (Faced/ UFBA).
No âmbito das artes, observa-se pouca atenção à produção artística da criança na escola ou fora dela, sendo ainda parcos e recentes os estudos sobre os modos de fruição e de criação infantil.

Com a ampliação das pesquisas sobre a infância em áreas diversas, é possível, hoje, compreender a criança como sujeito de desejo, pertencente a uma classe social, portadora de direitos, protagonista e produtora de saberes, linguagens e culturas. Desse modo, podemos afirmar que as artes e as brincadeiras são experiências de cultura, pois, em sua imersão, a criança representa e ressignifica o que sente, pensa e faz, produzindo sentidos, linguagens e culturas, conforme Brougère (1998, p. 3) afirma:

Toda interação supõe efetivamente uma interpretação das significações dadas aos objetos dessa interação (indivíduos, ações, objetos materiais), e a criança vai agir em função da significação que vai dar a esses objetos, adaptando-se à reação dos outros elementos da interação, para reagir também e produzir assim novas significações que vão ser interpretadas pelos outros. A cultura lúdica resulta de uma experiência lúdica, é então produzida pelo sujeito social.

Assim, a cultura da infância não existe de forma isolada à do adulto; ao contrário, essas diferentes culturas dialogam e, muitas vezes, se confrontam num conjunto de relações de poder, nas quais o adulto é detentor de um conjunto de práticas e valores sociais já sedimentadas e se coloca no lugar de mediação entre a criança e a cultura. Isso nos faz considerar que a experiência de cultura não pode ser transferida de um sujeito para o outro, pois nesse campo de negociações e de relacionamento, os sujeitos (adultos ou infantes) se constituem. Todos os sujeitos, são, portanto, coprodutores de cultura.

É nesse contexto, que apresentamos o Sarau Infantil Toda Criança é um Poema, ${ }^{1}$ uma experiência pluricultural e interdisciplinar, originada no campo da extensão universitária e oferecida para as crianças. É uma ação que contempla e valoriza a infância no campo acadêmico e propõe a produção de estudos sobre as culturas da infância, como também implementa e amplia as experiências artísticas e brincantes na formação de professores. Isto porque nem sempre o ensino superior converge para experiências artísticas, estéticas e brincantes em seu cotidiano, mesmo no curso de Licenciatura em Pedagogia, que é o lócus de formação legítimo de professores da infância. 
Muitas vezes, o que observamos é uma formação para professores sustentada no ensino de estudos sobre os fundamentos teóricos basilares da área educacional, com poucas vivências no campo do brincar e das artes, sem promover aprendizagens que priorizem, na sua prática, este tipo de experiência. Isto, sem dúvida, requer três aspectos fundamentais em sua natureza, ou seja, imersão, sentido e experiência vivente. É preciso que haja espaços, tempos de experiências com o brincar em suas várias formas, em seus diversos tipos e criações, além de vivências participativas em artes, pois, de outra maneira, torna-se difícil para esse profissional estimular a prática artística e o potencial criativo das crianças nas creches e pré-escolas. É possível ser professor de crianças sem ter experimentado as facetas, facilidades, dificuldades, alegrias, tristezas, desafios em seu próprio corpo? Seria possível ser professor(a) de criança, nesse tempo, sem ter vivido experiências com o brincar e com a arte? Isto, certamente, aponta reflexões sobre a formação de professores perpassada pelas artes e pelas culturas lúdicas infantis, além da revisão crítica dos modos de concepção de infância historicamente difundidos.

Desse modo, de maneira geral, o presente artigo oportuniza reflexões sobre a formação do pedagogo/a que pretende atuar com crianças, através de uma experiência de extensão universitária no âmbito das culturas da infância, o Sarau Infantil Toda Criança é um Poema, entendido como espaço/tempo de integração entre diferentes linguagens artísticas para crianças, a partir de ações de intercruzamento entre saberes e experiências de cunho sensível, o que explica o destaque para seu caráter interdisciplinar.

Dito isso, é importante ressaltar que, raramente, observamos saraus de natureza pluri-artística, interdisciplinar e destinados à infância, por isso, é relevante enfatizar também a necessidade de pesquisas e produção de conhecimentos nesse campo, uma vez que entendemos que "[...] a interdisciplinaridade se consolida na ousadia da busca, de uma busca que é sempre pergunta, ou melhor, pesquisa". (FAZENDA, 2009, p. 9) É desse modo, que entendemos a configuração do sarau artístico, ou seja, de forma interdisciplinar e entrelaçada com a realização de pesquisas e, consequentemente, com a produção de conhecimentos.

No exercício de uma reflexão sobre a pertinência da utilização do sarau como possibilidade de educação perpassada pela sensibilidade artística, nos deparamos com alguns questionamentos 
cruciais e que norteiam a escrita desse texto. Quais princípios fundamentam a organização dos tempos e dos espaços nas experiências estéticas como o sarau infantil? Experiências de artes podem ser efetivadas sob o diálogo entre diferentes linguagens, ou cada linguagem é autônoma, sem relação com as demais? Quais contribuições a experiência do sarau infantil poderia favorecer aos cursos de Licenciatura em Pedagogia?

Para dar conta das questões apontadas, acima, realizamos uma pesquisa qualitativa fundamentada teoricamente nos conceitos sobre Artes, Interdisciplinaridade e Infâncias, além de analisar a experiência do III Sarau Infantil Toda Criança é um Poema que aconteceu na Faculdade de Educação da Universidade Federal da Bahia no ano de 2017. Trataremos, a seguir, deste percurso realizado no âmbito da experiência universitária.

\section{Artes na infância: uma perspectiva interdisciplinar}

A integração das artes é, sem dúvida, um dos assuntos bastante polêmicos e discutidos no âmbito das pesquisas e das práticas de arte-educação. Conceitos como interdisciplinaridade, multidisciplinaridade e transdisciplinaridade são constantemente revistos e ampliados no campo das pesquisas em educação, mas ainda pouco articulados à experiência escolar. Contudo, o debate parece-nos salutar, no que se refere a ampliar tais reflexões em torno de experiências artísticas com crianças, oportunizando espaços de experimentação e de criação sobre possíveis caminhos com arteeducação e com as culturas infantis na formação de professores da infância. Nesse texto, a nossa intenção é nos determos a evidenciar o caráter interdisciplinar que, acreditamos, permeou a experiência estética, artística e brincante que abordaremos.

Consideramos imprescindível a valorização da experiência artística/estética junto à primeira infância, pois a Lei de Diretrizes e Bases da Educação (LDBEN) no 9.394/96 (BRASIL, 1996) coloca a disciplina Arte como componente curricular obrigatório contemplando o ensino fundamental a partir do sexto ano, o que atende à demanda dos egressos dos cursos de licenciatura em Artes, deixando portanto uma lacuna na educação infantil e nos anos iniciais que tem como regentes, os pedagogos. Esses não são devidamente preparados para a valorização e fruição das Artes. 
Compreendemos que essa proposta atende a duas demandas: a introdução às artes nos anos iniciais e na educação infantil e a sua inserção na formação do pedagogo. Nesse sentido, traçamos a compreensão de que as artes possuem pontos de diálogo entre si, por não acontecerem de modo isolado; logo a educação, especialmente no campo da infância, precisa tratar de experiências pedagógicas de forma integrada. Além disso, ponderamos que o ato criativo é sempre subversivo, pois visa a alteração e a modificação do existente, portanto é um ato de rebeldia em que o criador percebe a realidade, manifesta-se diante dela, nega o estabelecido e cria novo modo de interpretar a realidade.

O ato educativo é complexo e requer conhecimentos variados, complementares, diversos e dinâmicos para sua realização. Ao considerar a complexidade do ato educativo, reafirmamos a natureza da experiência artística como plural, múltipla e dialógica. É nesse sentido que Caldas (2007, p. 17) afirma que:

\begin{abstract}
A nossa natureza é uma complexidade pluralista, uma trama multifacetada e polissêmica, uma árvore cheia de folhas. E se a Escola, como microcosmos dessa sociedade, tende a formatá-los racionalmente, a intervenção teatral vem subverter a norma inoculando no racional os vírus do múltiplo, do sensível, do diverso, da sombra e da poesia.
\end{abstract}

No entanto, como o próprio autor menciona, o nosso sistema de educação tende a restringir a experiência de vida à mera transmissão de modelos, técnicas, formas e procedimentos de criação artística. Da mesma forma, este modo de se compreender a educação também supervaloriza as ações ditas racionais e intelectuais, em detrimento a atividades de criação e fruição estética, de integração entre saberes e de ampliação das experiências lúdicas, corporais e integradoras, tão necessárias à infância. Em geral, os sistemas de ensino se adaptam a "uma visão marcadamente disciplinar, ao mesmo tempo que encaminha as crianças e jovens para percursos de vida competitivos, individualistas e solitários". (PACHECO, 2007, p. 12) Ao analisarmos tal contexto sob a égide da complexidade, buscamos questionar a relação linear, fragmentada, compartimentada e mecânica entre o conhecimento científico e a prática na sala de aula, evidenciando as relações distanciadas e hierarquicamente propostas no planejamento e nas propostas pedagógicas escolares. Nesse sentido, Fazenda (2009, p.23) destaca, 
no campo dos estudos sobre interdisciplinaridade, a importância de uma formação interdisciplinar de professores, como uma:

[...]Interação envolvente sintetizante e dinâmica, reafirmando a necessidade de uma estrutura dialética, não linear e não hierarquizada, onde o ato profissional de diferentes saberes construídos pelos professores não se reduzem apenas a saberes disciplinares. Começamos aqui a tratar de um assunto novo, recentemente pesquisado, denominado intervenção educativa, em que mais importante que o produto é o processo.

Desse modo, Fazenda (2009) rompe com a ideia de formação pautada na simplista, disciplinar e homogênea condução de finalidades, na qual os produtos finais da aprendizagem são mais valorizados do que o processo de criação. A complexidade abrange tanto as certezas quanto as incertezas do processo educativo, esse é, portanto, contrário ao processo de escolarização ancorado em resultados pré-estabelecidos. Nesse último, a ideia é transmitir conhecimentos e disponibilizar informações considerando o resultado ao final do processo formativo, o que na escolarização tradicional é determinado na culminância profissional. Já no processo educativo baseado em uma perspectiva estética e cultural, não são considerados apenas os resultados, mas como um desenvolvimento humano que não se encerra na profissionalização; ao contrário, se perpetua ao longo da existência. Assim, compreendemos quão importante é a educação na primeira infância, pois, nessa fase, é necessário que as crianças iniciem uma educação sensível, artística e estética compondo um repertório que será recorrido ao longo de suas vidas. Destacamos que a criança aprende por meio da ação direta no mundo, sendo imprescindíveis os espaços/tempos para brincar, interagir e produzir linguagens. Eis os elementos que norteiam as nossas reflexões sobre as artes integradas na infância.

De um modo geral, a arte é vista como um tipo de atividade restrita à fruição e à produção do adulto, sob a suposição de que as crianças possuem uma capacidade criativa reduzida ou ainda em desenvolvimento. Este tipo de postura é resultante de uma visão adultocêntrica de mundo, perspectiva criticada nas palavras da educadora Kramer (2006, p. 19):

Muitos estudos criticam a dominação que ainda está presente na educação infantil; o adultocentrismo marca as produções 
teóricas e as instituições. Reconhecer na infância sua especificidade - sua capacidade de imaginar, fantasiar e criar - exige que muitas medidas sejam tomadas. Entender que as crianças têm um olhar crítico que vira pelo avesso a ordem das coisas, que subverte o sentido da história, requer que se conheçam as crianças, o que fazem, de que brincam, como inventam, de que falam.

Da mesma forma, é comum observar que atividades de cunho brincante têm ganhado uma forte influência de correntes pedagógicas que tendem a engessar a experiência ludoestética da criança em formas didáticas de transmissão de conteúdos programáticos, reduzindo a sua dimensão estética e cultural. Ao observar a lacuna de espaços que valorizem a expressão, a troca e a vivência de práticas educativas com centralidade nas culturas da infância, bem como a ausência de experiências de integração artística voltadas para crianças, foi concebido e organizado um sarau infantil, compreendido como espaço/tempo de experimentação artística e de vivências lúdicas diversificadas.

$\mathrm{Na}$ contramão de uma perspectiva fragmentada e reducionista da experiência, destaca-se o sarau infantil como espaço interdisciplinar, polifônico e multicultural da infância. Propor um sarau infantil como atividade extensionista, em parceria com escolas públicas, visou suscitar a reflexão e a provocação da forma como os espaços físicos podem ser concebidos e vividos, como os espaços podem ser ambientados, além de como é possível incentivar as interações criança-criança, criança-adulto, criançamundo. Com isto, buscou-se ampliar as potencialidades de interação artística entre estudantes de Licenciaturas, concebendo e produzindo espaços-tempos de vivências brincantes e artísticas, compreendidos também como campo de formação de professores no âmbito das culturas infantis. Nesse sentido, o Sarau Infantil Toda Criança é um Poema será analisado a seguir, como possibilidade de contribuir para a produção de novas formas de interações entre crianças e adultos em ambientes estéticos planejados para garantir a livre ação e interação dos sujeitos participantes desta experiência de cunho artístico. 


\section{Toda criança é um poema: princípios basilares do sarau infantil e seus espaços}

O Sarau Infantil Toda Criança é um Poema é tomado como objeto de estudo, no sentido de criar, registrar, discutir, analisar e difundir as possibilidades de construção de práticas artísticas, lúdicas, estéticas, sensíveis e educativas para a infância. O sarau é compreendido como um conjunto de espaços coletivos de fruição e experimentação simultânea ou de confluência artística que reúnem fazedores da cultura, em compartilhamento de suas expressões nas áreas de música, poesia, performances, teatro, audiovisual, dança, artes visuais, dentre outras linguagens. Com isso, visa-se ampliar o convívio e a troca de experiências entre crianças, estudantes, professores, servidores, artistas e outros criadores no ambiente universitário.

Com a realização da terceira edição do sarau infantil, buscou-se propiciar espaços/tempos de experiências de artes e experiências estéticas que provoquem estados de liberdade, de distensão, do aleatório, da escolha, do diálogo, em experiência viva, dentro do espaço acadêmico. Nesse tipo de experiência vivida na universidade, foi possível notar o que Friedmann (2014, p.95) afirma:

O brincante troca, socializa, coopera e compete, ganha e perde. Emociona-se, grita, chora, ri, perde a paciência, fica ansioso, aliviado. Erra, acerta. Põe em jogo seu corpo inteiro: suas habilidades motoras e de movimento vêm-se desafiadas. No brincar, o ser humano imita, medita, sonha, imagina. Seus desejos e seus medos transformam-se, naquele segundo, em realidade. O brincar descortina um mundo possível e imaginário para os brincantes. O brincar convida a ser eu mesmo.

A partir dessas impressões sobre o brincar propriamente dito, e sobre quem brinca, observa-se que as culturas lúdicas, nas quais as artes se incluem, apresentam um terreno fértil para a construção da leitura de mundo pela criança e para a efetivação de vínculos afetivos e sociais, bem como proporcionam vivências estéticas e pluriculturais. Nessas redes de interações, a criança amplia seus esquemas cognitivos e emocionais diante de uma brincadeira, jogo, ou atividade artística, em tentativas, conquistas, derrotas, que propiciam a composição do seu repertório simbólico, artístico e estético e de experiência-no-mundo. 
O Sarau Infantil Toda Criança é um Poema é um dispositivo de articulação, mobilização e culminância de processos formativos no âmbito do ensino, pesquisa e extensão da Faculdade de Educação (UFBA). Porém, inicialmente, foi pensado no campo extensionista, no sentido de promover espaços/tempos de diálogos e interações entre crianças, artistas, brincantes e educadores. No âmbito da educação da infância, é fundamental compreender o ambiente de convivência entre crianças "como um lugar de bem-estar, alegria e prazer, um espaço aberto às experiências plurais e de interesses das crianças e das comunidades". (FORMOSINHO, 2013, p. 44)

Na programação do III Sarau Infantil Toda Criança é um Poema, ocorrido em 2017, foram disponibilizados, gratuitamente, na Faculdade de Educação da UFBA, espaços artístico-culturais gratuitos e abertos a todos aqueles que desejassem compartilhar experiências estéticas e culturais. Assim, poetas, contadores de histórias, músicos, palhaços, artistas de uma forma geral e todas as almas dançantes foram convidados para esta festa de compartilhamento de ideias, experiências, vínculos e aprendizados mútuos.

O Sarau Infantil se configura em um espaço de brincar livre, fluído, de complexidade de convergência das diversas artes, linguagens, jogos e brincadeiras, com possibilidades simultâneas de acontecimentos para livre escolha das crianças, enquanto espaços, tempos e "[...] territórios plurais de vida, experiência e aprendizado [...]. Nesse sentido, a organização do espaço não é permanente". (FORMOSINHO, 2013, p. 45) Nos diversos espaços do sarau, as crianças puderam brincar, jogar, apreciar ou fazer arte, sem a imposição de fronteiras ou controles, sem paredes ou divisões por idade, se caracterizando como um espaço holístico e multirreferencial.

Avaliamos que as práticas pedagógicas voltadas para a infância representam valores e modos de pensar e de conceber os espaços de convivência da criança de forma dinâmica, diversificada e plural. Contudo, nem sempre este posicionamento é considerado e os espaços físicos, ou os ambientes educativos preparados para criança, muitas vezes, são utilizados como forma de controlar e disciplinar os corpos e as interações das crianças. Desse modo, Horn (2004, p. 27) evidencia, em seus estudos, que:

Na educação infantil, é comum os arranjos espaciais não permitirem a interação entre as crianças, impossibilitando sua apropriação dos espaços através de objetos, desenhos e nomes.

revista entreideias, Salvador, v. 8, n. 2, p. 211-232, maio/ago. 2019241 
A própria prática docente desenvolvida em muitas instituições de educação infantil defende o espaço como aliado ao controle dos corpos e dos movimentos considerados importantes no que é entendido como pré-alfabetização.

Conforme a autora, de um modo geral, os espaços físicos onde as crianças vão interagir, geralmente, são ocupados por mobiliários com baixa mobilidade e com poucas formas de interação. Os espaços físicos não são neutros e expressam o modo de ver a criança e suas práticas formativas. Geralmente, as demandas do adulto são consideradas em detrimento às necessidades das crianças; muitas vezes, os ambientes são mal planejados e não são constantemente revistos, modificados ou atualizados, restringindo as oportunidades de interação e de desenvolvimento da identidade pessoal e cultural da criança.

Com vistas a problematizar esta relação entre ambientes e infâncias, O III Sarau Infantil Toda Criança é um Poema, fruto de resultado de construção coletiva entre estudantes e professores, foi organizado em quatro espaços educativos, a saber: 1.Visualidades, 2.Musicalidades, 3.Brincadeiras e Interações; e 4.Poemas e Histórias. Vale salientar que apesar dessa organização, os espaços foram bastante flexíveis e as atividades aconteceram ao mesmo tempo e de forma simultânea, sob a compreensão destacada por Oliveira (2002, p. 26):

A grande flexibilidade do pensamento da criança e seu constante desejo de exploração requerem a organização de contextos propícios de aprendizagem. A criatividade emerge das múltiplas experiências infantis, visto que ela não é um dom, mas se desenvolve naturalmente se a criança tiver liberdade para explorar situações com parceiros diversos.

As múltiplas experiências oportunizadas à criança não consistem, no entanto, em divisão ou fragmentação desses espaços. Aqui não cabe a separação, na qual a criança adentra um espaço e, numa dada marcação de um determinado tempo cronológico, adentra outro. A ideia foi construir e organizar espaços que provocassem as interações e o diálogo entre diferentes crianças, mas que as fronteiras metodológicas e limites espaciais se dissolvessem e se integrassem por meio da ação e da sua reconstrução pelas crianças, visando à confluência de saberes e práticas. Nesse ponto, é importante afirmar que "a noção-chave da interdisciplinaridade é a interação entre as disciplinas, que pode 
ir da simples comunicação de ideias até a integração mútua dos conceitos, da terminologia, da metodologia, dos procedimentos". (MACEDO, 2000, p. 51) No caso do sarau infantil, o conjunto de experiências estéticas se desenrolou sem contornos disciplinares comuns ao âmbito escolar e universitário, criando uma dinâmica própria, com movimentos, sons, gestos, cheiros, interações próprias do público infantil e contribuindo bastante para a comunicação e a integração mútua entre diferentes experiências artísticas. Foi possível notar uma reciprocidade mútua e integração entre as diferentes propostas de educação estética disponibilizadas no sarau infantil.

No III Sarau Infantil Toda Criança é um Poema, pôde-se perceber, em um mesmo espaço, a confluência e o diálogo entre diferentes linguagens artísticas. O espaço visualidades foi concebido como o campo de percepção estética visual, proporcionando também a expressão das crianças com cores, formas e texturas. Considerando que a criança já vive em um grande universo social composto por imagens e formas, no sarau, foi realizada uma exposição de telas e fotografias produzidas por estudantes do Programa Institucional de Bolsas de Iniciação à Docência (Pibid) do curso de Licenciatura em Pedagogia da UFBA; instalações e exposição das turmas de Licenciatura em Artes visuais da FACED, além de brinquedos e demais objetos produzidos pelos estudantes no componente de Práticas em educação infantil e, juntamente com as crianças das escolas públicas, em atividades de estágios curriculares supervisionados da Licenciatura em Pedagogia, disponibilizados por todos os espaços do evento. Por meio do desenho, a criança é capaz de representar imagens que evidenciam a sua sensibilidade, percepção, invenção que podem, inclusive serem apropriadas por outras crianças e pelos adultos. Sem dúvida, as interações garantiram essas apropriações dos espaços, dos corpos e dos materiais utilizados, na medida em que as crianças realizaram ações diversas, desde a apreciação estética de fotografias, imagens e telas à experimentação plástica dos elementos disponíveis no espaço como tintas orgânicas, pintura dos corpos com argilas de tonalidade de cores diferentes.

A visualidade, enquanto linguagem artística significativa, esteve presente em todos os espaços do Sarau Infantil, sem divisões ou fragmentações espaciais. Destacamos a dimensão estética visual de todo o sarau infantil, compondo uma rica explosão de 
cores, formas e texturas, com vistas a aguçar o olhar das crianças e também dos adultos presentes no sarau. Diversos elementos visuais ambientaram o espaço do sarau infantil, sob a compreensão da dimensão estética do processo formativo segundo o que Duarte Júnior (2001, p. 171) afirma:

A educação da sensibilidade, o processo de se conferir atenção aos nossos fenômenos estéticos, vai se afigurando fundamental não apenas para uma vivência mais íntegra e plena do cotidiano. [...] Uma educação que reconheça o fundamento sensível de nossa existência e a ele dedique a devida atenção, propiciando o seu desenvolvimento, estará, por certo, tornando mais abrangente e sutil a atuação dos mecanismos lógicos e racionais de operação da consciência humana.

Assim, valorizar as artes na experiência de mundo da criança é investir na formação de pedagogos que abranja não apenas aspectos racionais e conteudistas, mas que amplie as dimensões sensíveis e criativas da experiência humana.

Musicalidades, o segundo espaço do sarau infantil, contou com a diversidade de ritmos e sonoridades presentes em manifestações das culturas populares, como na capoeira, no bumba-meu-boi e o samba, por meio das quais as crianças cantaram, confeccionaram e tocaram instrumentos, acompanharam as apresentações musicais das escolas e dos grupo culturais convidados. Houve participação de crianças em apresentações musicais com as famílias, momentos de partilhas e de envolvimento pleno com a arte de escutar. Buscouse, assim, favorecer ao campo de percepção rítmica e de produção musical, como uma das linguagens produzidas e apreciadas por crianças e adultos.

O terceiro espaço foi nomeado de Brincadeiras e Interações e caracterizou-se pela riqueza de experiências não diretivas e pela oferta de objetos não estruturados que mobilizam a imaginação infantil e a ação livre do brincar. Vale dizer que as brincadeiras e as interações são entendidas, nessa pesquisa, como os dois eixos do currículo da Educação Infantil referenciados nas Diretrizes Curriculares Nacionais para a Educação Infantil (BRASIL, 2010).E são nesses momentos de brincadeiras e de interações diversas que estabelecidas entre corpos, espaço e artistas que são criadas formas muito diversificadas de formação, de vínculos e de produção de linguagens, pois as crianças "produzem a primeira de uma série de 
culturas de pares nas quais o conhecimento infantil e as práticas são transformadas gradualmente em conhecimento e competências necessárias para participar no mundo adulto". (CORSARO, 2002, p. 114) Deste modo, diversos materiais não estruturados, como tampinhas, canudos, copos plásticos, bacias, palitos de picolés, tintas e papeis ficaram acessíveis para as crianças procederem com as suas criações. Entende-se por materiais não-estruturados os objetos que não foram produzidos para o brincar, mas que as crianças dão sentidos e os transformam em matéria para a criação, a expressão e para a brincadeira. Foi comum observar torres de bacias serem construídas com muito afinco para depois serem desconstruídas ao som de um grito de satisfação. "Oba!", "Vamos de novo!", "Agora é a minha vez". Esses momentos, vale dizer, foram bastante disputados e, apesar do constante som alto das bacias sendo derrubadas ou arrastadas no chão, não incomodava o andamento da brincadeira, pois esse som era próprio daquela cena, por isso não soava estranho para quem estava imerso nesta experiência. As interações e brincadeiras aconteciam de forma tão entrelaçadas que podíamos afirmar que uma não acontece sem a outra.

Por último, o espaço nomeado de Poemas e Histórias foi organizado com histórias, parlendas, sussurros poéticos e travalíngua, com ou sem rimas, com o intuito de brincar com o jogo sonoro das palavras, como proposta prática deste universo linguístico da infância. Foi oportunizado também o contato e a interação com artistas e contadores, além da liberdade de ler histórias, como uma forma de inserção das crianças no mundo da palavra escrita, ainda que, em alguns casos, elas não soubessem ler de forma convencional. Isso foi muito importante por se tratar de ações pedagógicas de aproximação da criança no universo da oralidade da cultura de modo lúdico, sensível e experiencial.

As crianças foram recepcionadas, no III Sarau Infantil Toda Criança é um Poema, por sussurradoras poéticas que falavam poemas em seus ouvidos e elas demonstravam seus sentimentos, através dos gestos explicitados ou das verbalizações. "Quero outra!", "Quero ouvir!", "Quero mais!", "Gostei daquela!". Assim como também foi possível notar algumas crianças querendo experimentar ser as próprias sussurradoras. Esses modos de produção e interação linguística no universo infantil tiveram importante destaque na organização do Sarau, pois se congregou artistas, brincantes 
e demais interessados em compartilhar suas experiências de contação de histórias, narração de poemas e brincadeiras de natureza oral para que as crianças tivessem acesso a elas. Assim, um espaço dentro do sarau foi pensado com vistas a servir de palco para essas trocas.

Vale salientar que o diálogo com as expressões artísticas, como a contação de histórias, o teatro, a poesia e a música, marcou o Sarau Infantil com a presença de diversos gêneros e linguagens. As canções de capoeira foram registradas com a participação das crianças que apresentaram cantigas populares acompanhadas por voz e violão, além de outros instrumentos musicais e experimentações sonoras diversas. O repertório de músicas, poemas, histórias integra os conhecimentos da cultura popular brasileira e das culturas infantis, garantindo uma grande variedade de gêneros nos elementos da música. Desse modo, a diversidade e a pluralidade de experiências culturais, estéticas e artísticas foram marcas identitárias do sarau infantil.

Dito isto, como mensurar respostas objetivas às perguntas apontadas no início do texto a respeito do III Sarau Infantil Toda Criança é um Poema? É possível dizer sobre os princípios que fundamentam a organização dos tempos e dos espaços nas experiências estéticas como o sarau infantil? Experiências de artes podem ser efetivadas sob o diálogo entre diferentes linguagens, ou cada linguagem é autônoma? Quais contribuições a experiência do sarau poderia trazer para os cursos de Licenciatura em Pedagogia? É isto que veremos adiante, tomando como base algumas interpretações, análises e resultados encontrados na experiência desse sarau infantil.

\section{Sarau infantil Toda Criança é um Poema: discussão, análises e resultados}

O III Sarau Infantil Toda Criança é um Poema foi o campo selecionado nesse estudo. É um espaço rico em elementos significativos e potentes para a construção de um diálogo sobre a formação do pedagogo, entrelaçada pelas artes e dedicada à educação infantil. Vale salientar que foi possível encontrar respostas sobre o modo de organização do sarau infantil, considerando o caráter interdisciplinar, como principal. 
Sem dúvida, uma pesquisa qualitativa, de cunho social e artístico, tendo como abordagem a pesquisa com crianças, adotada, inclusive, como norte teórico-metodológico. A experiência extensionista do sarau infantil é tomada como dispositivo empírico de produção de conhecimentos sobre as linguagens artísticas da infância, em uma perspectiva interdisciplinar. Alicerça a este campo o princípio de que a criança é ativa, pertencente a uma geração, a uma classe social, além de ser portadora de direitos e de linguagens próprias e, portanto, é produtora de cultura.

Interessa-nos investigar as experiências artísticas propostas no sarau infantil, evidenciando a sua diversidade de espaços, linguagens e interações. No sarau infantil, as crianças são os principais atores sociais responsáveis pela sua realização, em diálogo com os artistas e grupos culturais. Do ponto de vista metodológico, vale salientar que "se as crianças interagem no mundo adulto porque negociam, compartilham e criam culturas, necessitamos pensar em metodologias que realmente tenham como foco suas vozes, olhares, experiências e pontos de vista". (DELGADO e MÜLLER, 2005, p. 353).

Nesse sentido, quando perguntamos às crianças sobre o que mais gostaram do sarau infantil, algumas respostas foram dadas imediatamente, como "De tudo", "gostei mais da poesia e das histórias"; "Gostei da música e das brincadeiras"; "Eu amei empilhar as bacias até o teto". E quando questionadas a respeito do que não gostaram do sarau, responderam "Eu não gostei porque acabou", "E eu queria que o sarau das crianças terminasse só amanhã", "Só foi muito rápido"; "Que dia eu vou voltar aqui na faculdade?". As falas das crianças anunciam a necessidade de tempo para o brincar e para este exercício de liberdade garantido pela metodologia do sarau infantil. Suas vozes demonstram suas escolhas e desejos e revelam um sentido sobre o ambiente universitário, ao perguntarem "Que dia eu vou voltar aqui na faculdade?"; ainda que este lugar seja, prioritariamente destinado a adultos, para as crianças, esta experiência provocou a produção do significado da universidade como um lugar acolhedor, diverso e não hostil, uma vez que suscitou o desejo de retornar a este espaço.

A escuta das vozes das crianças sobre suas experiências artísticas, ali, vividas foi fundamental para o avanço das nossas pesquisas com crianças. Ou seja, desde a primeira versão do sarau infantil, escutamos e buscamos constituir espaços criativos para

revista entreideias, Salvador, v. 8, n. 2, p. 211-232, maio/ago. 2019247 
a sua fruição e criação livre. Tais vivências artísticas consideram os saberes de cada criança individualmente e valorizam suas potencialidades e apresentam características do universo infantil e diferentes das atividades artísticas produzidas pelos adultos. Mesmo o sarau sendo uma atividade artística concedida e desenvolvida por adultos é possível sua estrutura ser inspiradora para sua aplicação com as crianças em seus mundos, como afirmam Martins Filho e Prado (2011, p.2):

$[\ldots]$ a complexidade das infâncias instigando-nos a investir nos saberes das próprias crianças, não para reafirmar as incapacidades que a elas foram atribuídas, mas para destacar um conjunto de peculiaridades positivas que diferem as crianças dos adultos.

As experiências estéticas, artísticas e brincantes das crianças são compostas de sentidos e significados que as constituem como sujeitos que, ao mesmo tempo, são produzidos e são produtores de culturas. Nosso interesse consiste em conhecer as narrativas das experiências escolhidas pelas crianças para serem compartilhadas com o público adulto, como modo de provocar reflexões sobre infância e experiência artística. Percebemos que o que é narrado pela criança nem sempre coincide com o que de fato aconteceu, mas configura-se apenas como uma interpretação carregada de significados que ela própria produz para compartilhar com o outro. A experiência humana é um fenômeno complexo, marcado por múltiplas referências, e por este motivo, "não se ex-plica, ou seja, não se fala dela de fora dela, se com-preende, porque, para esse fim, o outro, seu discurso, suas ações e projeções são indispensáveis". (MACEDO, 2000, p. 26) Dessa forma, o próprio ato de narrar também se constitui numa experiência, uma situação na qual ela articula os sentidos e significados da situação narrada às expectativas que ela projeta no seu interlocutor.

$\mathrm{Na}$ nossa experiência com o sarau infantil e mais especificamente, na sua terceira edição, foi possível organizar e constatar quatro espaços presentes (visualidades, musicalidades, brincadeiras e interações e poemas e histórias) e que funcionaram de forma simultânea, como já foi relatado, anteriormente. Desse modo, é possível afirmar que os espaços podem e devem ser organizados de forma interdisciplinar no que diz respeito as diversas linguagens, pois assim funcionam, se movimentam e assumem uma dinâmica própria. As várias linguagens, evidenciadas nos espaços 
apresentados no III Sarau Infantil Toda Criança é um Poema, apesar de funcionarem tão imbricadas, muitas vezes tão entrelaçadas uma com as outras, não perdem e nem se esvaziam no que se refere às suas singularidades. É notória a presença constante da música e das visualidades em todo ambiente do sarau, mas nenhuma dessas linguagens deixa de marcar as suas características e especificidades quando dialogadas entre si. As crianças sabem disso e revelam e desfrutam dessa mistura, mas, por outro lado, não deixam de apreciar e experimentar de forma singular cada uma delas.

A constatação desses espaços e a sua forma específica de acontecer não é de modo algum marcada pelo tempo cronológico, pois permite que as crianças exercitem a sua autonomia, a sua possibilidade de escolha e, quem sabe também, a sua frustração em não poder experienciar tudo quanto for possível. Afinal, faz parte dessa proposta, não? Por outro lado, fica evidenciada que a qualidade do tempo dedicado aos espaços pelas crianças não é referenciada pelo tempo ditado por outro. Afinal, como saber que está na hora de mudar de um espaço para outro ou permanecer mais um pouquinho naquele espaço que já passamos quase a tarde inteira? Como ter certeza de que é hora de ouvir história se os olhos das crianças estão parados no deleite das brincadeiras com as bacias coloridas espalhadas por todo o chão? Certamente, estamos nos referindo a um tempo que é de cada criança e que ela bem sabe sobre isso. Estamos diante de um tempo que é lógico, ou seja, o tempo do sujeito, independente da sua cronologia. Sem dúvida, um grande desafio para as escolas e educadores que insistem, frequentemente, em ditar o tempo em que a criança pode ou deve brincar, inclusive, muitas vezes, determinando até os tipos de brincadeiras que se deve praticar.

O sarau infantil revela, ainda, que os tempos e espaços são vividos de forma intensa pela criança e que a todo momento é possível refazer os espaços com seus tempos. É certo que para cada espaço organizado no sarau infantil existia objetos, pessoas, instrumentos, rituais específicos e que carregavam linguagem ou linguagens singulares, porém nada disso é tão determinado que não possa ser construído e desconstruído pelos sujeitos que nele se encontram imersos. Os espaços e tempos dialogam entre si e produzem sua própria dinâmica. As crianças que utilizaram o espaço das brincadeiras e interações, por exemplo, aceitaram o convite para nele interagirem, mas com certeza o transformaram, a 
partir do que levaram de si e do que puderam inventar, ali, naquele determinado tempo.

Se tínhamos uma preocupação com a formação dos pedagogos, essa experiência nos mostra que a nossa preocupação é procedente, pois, muitas vezes, o que vemos nos cursos de graduação em pedagogia é a não contemplação de uma experiência, ou melhor, de múltiplas experiências de linguagens, de artes, de saberes que perpassem sobre a sua identidade docente. Estamos marcando a necessidade de se viver experiências, de saber, por exemplo, sobre uma brincadeira porque pôde, primeiro, brincar e se interrogar sobre ela. Ou, ainda, poder escolher uma história, porque antes pôde fazer a sua leitura e experimentar as suas várias versões por tantas vezes se fez necessário. Para se formar um professor da educação infantil é fundamental a vivência, o desafio das desconstruções e reinvenções que perpassem pelos vários modos de se viver infâncias.

\section{Considerações finais}

Com vistas a valorizar as infâncias e suas culturas brincantes, e estimular vivências estéticas, sensíveis e artísticas, a Faculdade de Educação da UFBA realizou, no ano de 2017, o III Sarau Infantil Toda Criança é um Poema, constituído por espaços vivos de diversão, afeto, interações e brincadeiras entre crianças e adultos. Produzido por professores e estudantes, o sarau infantil contou com uma estrutura repleta de brinquedos, oficinas, contação de histórias, recital de poemas, pinturas, invenções, brincadeiras e divertimentos propostos por artistas e brincantes parceiros do Projeto de Extensão Balaio de Sensibilidades.

Esse ato lúdico marcou o entendimento de que a criança precisa de espaços/tempos/atividades brincantes, sensíveis, artísticas, estéticas e afetivas e que a universidade tem o papel importante de provocar reflexões e promover formas de integração coletivas e criativas. Por esta razão, considerou-se como uma oportunidade de experimentação de um formato de atividades voltadas para as crianças e de registrar reflexões em torno da interação entre as artes proposta em espaços e tempos que contemplassem uma gama de possibilidades de brincadeiras e interações de forma simultânea e assumindo um caráter interdisciplinar em relação às linguagens artísticas. 
O texto abordou sobre os princípios e as formas de organização de espaços/tempos estéticos do III Sarau Infantil Toda Criança é um Poema, constituído por diferentes ambientes artísticos, como visualidades, musicalidades, brincadeiras e interações e poemas e histórias, numa perspectiva interdisciplinar. Os espaços de linguagem artística foram concebidos de modos diferentes, sendo fruídos, vividos e dinamizados pelas crianças de forma mais livre e menos direcionada possível, respeitando a natureza tanto das artes, como da infância.

Ao tecermos reflexões sobre o sarau infantil, retomamos as perguntas norteadoras a fim construir sínteses sobre a experiência: Quais princípios fundamentam a organização dos tempos e dos espaços nas experiências estéticas como o sarau infantil? Experiências de artes podem ser efetivadas sob o diálogo entre diferentes linguagens, ou cada linguagem é autônoma, sem relação com as demais? Quais contribuições a experiência do sarau infantil poderia favorecer aos cursos de Licenciatura em Pedagogia? Desse modo, salientamos que o III Sarau Infantil Toda Criança é um Poema, compreendido como espaço/tempo de aprendizagem e de interação entre as artes e crianças de diferentes idades, apresentou oito resultados fundamentais: 1 . a liberdade do brincar e do interagir - entendido como sendo o direito das crianças em escolher o momento da brincadeira começar, mudar e terminar, o que fazer, quando fazer e como fazer; 2. a simultaneidade das atividades propostas; 3. o diálogo entre brincantes, artistas, educadores e crianças; 4 . a articulação entre a universidade e a educação básica; 5. a formação lúdica de educadores; 6. a ampliação do repertório estético, cultural e brincante de estudantes em formação; 7. a ausência de fronteiras entre as experiências artísticas, ou seja, as artes se integraram em seus espaços que se imbricaram, muitas vezes, em um acontecer poético integrado; 8. a realização do sarau infantil situa o professor em formação no lugar da ação, do fazer, estimulando o seu potencial criador e favorecendo a ampliação do olhar reflexivo sobre as artes e as infâncias.

Concluímos que, com base nesses resultados alcançados, podemos considerar que o sarau infantil, como ação estética e de natureza extensionista, pode favorecer o convívio e a cultura universitária, a troca de experiências entre estudantes, professores, servidores, artistas e outros criadores. Além disso, o sarau infantil pode ainda permitir o partilhamento da integração de várias 
linguagens artísticas, confluindo-asem um mesmo espaço dedicado às crianças interdisciplinarmente. Essa experiência pode ainda provocar o desejo de olharmos atentamente para as possibilidades que uma atividade dessa natureza pode proporcionar para os professores envolvidos, os artistas participantes, os espectadores e, principalmente, para as crianças que de forma lúdica criam e fruem a experiência artística, estética e brincante.

\title{
Art, interdisciplinarity and childhood: a esthetic, artistic and playful experiences in the sarau Every Child is a Poem
}

\begin{abstract}
This text reflects on artistic experiences experienced in childhood, having as basic principle the child's understanding as being able to enjoy, create and produce cultures. A bibliographical research was conducted with significant authors. A field research was developed based on the "III Child Sarau Every Child is a Poem", an integral part of the Hamper Sensibility Extension Project, linked to the Faculty of Education of the Federal University of Bahia. In this edition, children from 4 to 8 years old participated and it was possible to observe four types of spaces: visualities, musicalities, jokes and interactions and poems and stories, organized with reference to diversified languages, but in an interdisciplinary way. The study revealed that the field of children's cultures covers distinct areas of artistic knowledge and their own varied forms of interactions and production of knowledge and experience. It was possible to conclude as basic principles of the aesthetic experience of the Children's Sarau: a) diversity of experiences and artistic languages; b) space-time organized and characterized by possibilities of disorder, flexibility and reversibility; c) freedom of action of the child in choosing the forms of interaction with the arts; d) dialogical relationship between adults and children and children with each other. It was inferred that the Children's Sarau can be considered an aesthetic, artistic, playful, plural, free experience and with different possibilities of interactions between children, artists, schools, academics and jokers.
\end{abstract}

Keywords: Childhood. Aesthetics. Art. Children's culture. Play.

\section{El art. la interdisciplinaridad y la infancia: experiencias esteticas, artisticas y juegos en el sarau Todo Niño es un Poema}

Resumém: Este texto hace reflexiones sobre experiencias artísticas vivenciadas en la infancia, teniendo como principio basilar la comprensión del niño como ser capaz de frucir, crear y producir culturas. Se realizó una investigación bibliográfica con autores significativos. Se desarrolló una investigación de campo tomando como base el III Sarau Infantil Todo Niño es un Poema, acción integrante del Proyecto de Extensión Canasta de Sensibilidades, vinculado a la Facultad de Educación de la Universidad Federal de Bahía. Em esta edición participaron niños de 4 a 8 años y fue posible observar cuatro tipos de espacios (Visualidades, Musicalidades, Juguetes e Interacciones y 
Poemas e Historias), organizados con referencia a lenguajes diversificados, pero de forma interdisciplinaria. El estudio reveló que el campo de las culturas infantiles abarca áreas distintas del conocimiento artístico y formas propias y variadas de interacciones y de producción de saberes y experiencias. Fue posible concluir como principios basilares de la experiencia estética del Sarau Infantil: a) diversidad de vivencias y de lenguajes artísticos; b) espacio-tiempo organizado y caracterizado por posibilidades de desorden, flexibilidad y reversibilidad; c) libertad de acción del niño en elegir las formas de interacción con las artes; d) relación dialógica entre adultos y niños y de los niños entre sí. Se ha inferido que el Sarau Infantil puede ser considerado una experiencia estética, artística, bromeante, plural, libre y con diferentes posibilidades de interacciones entre niños, artistas, escuelas, académicos y bromeantes.

Palabras clave: Infancia. Estética. Arte. Cultura infantil. Jugar.

\section{Referências}

BRASIL. Ministério da Educação. Conselho Nacional de Educação. Resolução CNE/CEB 5/2009. Fixa as Diretrizes Curriculares Nacionais para a Educação Infantil. Diário Oficial da União, Seção 1, p.18. Brasília, DF, 18 dez. 2009.BRASIL. Lei n. 9.394, de 20 de dezembro de 1996. Estabelece as diretrizes e bases da educação nacional. Diário Oficial da União, Brasília, DF, 23 dez. 1996. Disponível em: http://portal.mec.gov. br/arquivos/pdf/ldb.pdf. Acesso em: 10 dez. 2017.

BROUGÈRE, Gilles. A criança e a cultura lúdica. Revista da Faculdade de Educação, São Paulo, v. 24, n. 2, 1998.

CALDAS, José. A nostalgia do inefável. In: PACHECO, Natércia.

CALDAS, José. TERRASÊCA, Manuela. Teatro e educação: transgressões disciplinares. Porto, Portugal: Edições Afrontamentos/CIIE, 2007.

CORSARO, W. A reprodução interpretativa do brincar ao "faz de conta" das crianças. Revista Educação, Sociedade e Culturas, nº 17. 2002. p. 113-114.

DELGADO, Ana Cristina Coll. MÜLLER, Fernanda. Pesquisa com crianças. Revista Educação e Sociedade, Campinas, v. 26, n. 91, p. 351360, maio/ago. 2005.

DUARTE JÚNIOR, João Francisco. O sentido dos sentidos: a educação (do) sensível. Curitiba: Criar Edições, 2001.

FAZENDA, Ivani Fazenda. Interdisciplinaridade e transdisciplinaridade na formação de professores. Revista Brasileira de Docência, Ensino e Pesquisa em Administração, Cristalina, v. 1, n. 1, p. 24-32, Maio2009.

FORMOSINHO, Júlia Oliveira. Modelos curriculares para a educação de infância: construindo uma práxis de participação. Porto, Portugal: Editora Porto, 2013.

FRIEDMAN, Adriana. O universo simbólico da criança: olhares sensíveis para a infância. 2014. Disponível em: http://territoriodobrincar.com. br/wp-content/uploads/2015/06/Adriana_Friedmann_O_Universo_ Simbolico_da_Crianca.pdf. Acesso em: 5 nov. 2017. 
HORN, Maria da Graça de Souza. Sabores, cores, sons, aromas: a organização dos espaços na educação infantil. Porto Alegre: Artmed, 2004.

MACEDO, Roberto Sidnei. Trajetória, itinerário, itinerância e errância no campo do currículo. In: REUNIÃO ANUAL DA ASSOCIAÇÃO NACIONAL DE PÓS-GRADUAÇÃO E PESQUISA EM EDUCAÇÃO: "EDUCAÇÃO NÃO É PRIVILÉGIO",23. 2000, Caxambu. Trabalho apresentado[...]. Caxambu: ANPED, 2000.

MARTINS FILHO, Altino José; PRADO, Patrícia. Das pesquisas com crianças à complexidade da infância. São Paulo: Autores Associados, 2011.

OLIVEIRA, Zilma Ramos. de. Educação Infantil: fundamentos e métodos. São Paulo: Cortez, 2002.

PACHECO, Natércia. Teatro/Escola: entre a sedução e o conflito. In: PACHECO, Natércia. CALDAS, José. TERRASÊCA, Manuela. Teatro e educação: transgressões disciplinares. Porto, Portugal: Edições Afrontamentos/CIIE, 2007.

Submetido: 10 de agosto de 2018 Aceito: 02 de junho de 2019 